\title{
Multiple anatomic sites of infarction in a pediatric patient with $M$. pneumoniae infection, a case report
}

\author{
Devon W. Hahn ${ }^{1 *}$ (D) Claire E. Atkinson ${ }^{2}$ and Matthew Le ${ }^{1}$
}

\begin{abstract}
Background: Although M. pneumoniae (M. pneumoniae) infections have been associated with various extrapulmonary manifestations, there have been very few documented cases of thrombotic events in pediatrics, and none to our knowledge with such extensive involvement as the patient described here. We aim to contribute to the urgency of discovering the mechanism of the coagulopathy associated with M. pneumoniae infections.

Case presentation: This 10-year-old boy was admitted after 2 weeks of fever, sore throat, worsening cough, and progressive neck and back pain. During hospitalization, he developed clots in several different organs: bilateral pulmonary emboli, cardiac vegetations, multiple splenic infarcts, and deep venous thromboses in three of four extremities. He was treated with long-term antibiotics and anticoagulation, and fully recovered.

Conclusions: This is the first case known to us of a child with an extensive number of thrombotic events in multiple anatomic sites associated with M. pneumoniae infection. The mechanism by which M. pneumoniae infection is related to thrombotic events is not fully understood, but there is evidence that the interplay between the coagulation pathways and the complement cascade may be significant. This patient underwent extensive investigation, and was found to have significant coagulopathy, but minimal complement abnormalities. By better understanding the mechanisms involved in complications of M. pneumoniae infection, the clinician can more effectively investigate the progression of this disease saving time, money, morbidity, and mortality.
\end{abstract}

Keywords: mycoplasma, Coagulopathy, Infarction, Embolism, Endocarditis, Pediatrics

\section{Background}

M. pneumoniae(M. pneumoniae) is a common infection in children, responsible for up to $40 \%$ or more of cases of community-acquired pneumonias and as many as $18 \%$ of cases requiring hospitalization in children [1]. Up to $25 \%$ of these patients experience extrapulmonary complications. The most commonly recognized extrapulmonary complication is central nervous system

\footnotetext{
* Correspondence: Devon-Hahn@ouhsc.edu

'Department of Pediatrics, University of Oklahoma Health Sciences Center, 1200 Children's Avenue, A1 Room 12305, Oklahoma City, Oklahoma 73104, USA

Full list of author information is available at the end of the article
}

(CNS) involvement, and ranges from encephalitis to cranial nerve palsies to acute disseminated encephalomyelitis [1]. Dermatologic manifestations are also common, and occur in up to $25 \%$ of patients. Cardiac complications are uncommon, but have involved pericarditis, myocarditis, endocarditis, and cardiac tamponade, and may be related to direct detection of the organism in cardiac tissue or involve an autoimmune mechanism [2]. Septic arthritis, rhabdomyolysis, an assortment of nonspecific gastrointestinal symptoms, and renal complications (including acute glomerulonephritis, interstitial nephritis, nephrotic syndrome, and IgA nephropathy

(C) The Author(s). 2021 Open Access This article is licensed under a Creative Commons Attribution 4.0 International License, which permits use, sharing, adaptation, distribution and reproduction in any medium or format, as long as you give appropriate credit to the original author(s) and the source, provide a link to the Creative Commons licence, and indicate if changes were made. The images or other third party material in this article are included in the article's Creative Commons licence, unless indicated otherwise in a credit line to the material. If material is not included in the article's Creative Commons licence and your intended use is not permitted by statutory regulation or exceeds the permitted use, you will need to obtain permission directly from the copyright holder. To view a copy of this licence, visit http://creativecommons.org/licenses/by/4.0/ The Creative Commons Public Domain Dedication waiver (http://creativecommons.org/publicdomain/zero/1.0/) applies to the data made available in this article, unless otherwise stated in a credit line to the data. 
presumable as a result of immune complex formation), have all been identified [2].

.Although M. pneumoniae infections have been associated with various extrapulmonary manifestations, there have been very few documented cases of thrombotic events in pediatrics, and none to our knowledge with such extensive involvement as the patient described here. We aim to contribute to the urgency of discovering the mechanism of the coagulopathy associated with $M$. pneumoniae infections.

\section{Case presentation}

A previously healthy 10-year-old male was admitted after 2 weeks of fever, sore throat, non-productive cough, progressive difficulty breathing, and worsening neck and back pain. Vital signs on admission revealed a fever of $38.1 \mathrm{C}$, pulse of 139 beats per minute, respiratory rate of 36 , and a blood pressure of $140 / 76 \mathrm{~mm} \mathrm{Hg}(\mathrm{mm} / \mathrm{Hg})$, but his oxygen saturations were $100 \%$ on room air. Inflammatory markers were elevated: C-reactive protein (CRP) $146 \mathrm{mg} / \mathrm{Liter}(\mathrm{mg} / \mathrm{L})$, procalcitonin 25 nanograms/milliliter $(\mathrm{ng} / \mathrm{mL})$, and lactate dehydrogenase (LDH) 1200 units/Liter. A chest $\mathrm{x}$-ray and chest computerized tomography (CT) showed a left upper lobe consolidation, and he was admitted to the hospital for severe sepsis and pneumonia. He was started on vancomycin and ceftriaxone.

On hospital day 3, he complained of increasing rightsided neck pain. Exam showed a febrile, ill-appearing boy, shivering, and fearful during exam, but he was alert and oriented. The right side of his neck was significantly tender with limited range of motion. He had significant diffuse non-tender scalp edema and mild edema of hands and feet as well, but did not complain of any pain in those areas. Chest exam revealed significantly diminished breath sounds over the left hemithorax, but no crackles or wheezing. He had nasal flaring while sleeping, and oxygen saturations of $>94 \%$ on 21 /minute of oxygen by nasal canula while both awake and asleep. Labs at that time showed a normal white blood cell count of 13.42 thousand/cubic millimeter $\left(\mathrm{K} / \mathrm{mm}^{3}\right)$, normal platelet count of $180 \mathrm{~K} / \mathrm{mm}^{3}$ and a hemoglobin of $8.9 \mathrm{~g} /$ deciliter $(\mathrm{g} / \mathrm{dL})$. Red blood cell indices showed a mean corpuscular volume (MCV) of 86 femtoliters (fL, or $\left.10^{-15} \mathrm{l}\right)$, a mean corpuscular hemoglobin $(\mathrm{MCH})$ of 26 picograms (pg), and a mean corpuscular hemoglobin concentration (MCHC) of $35.6 \mathrm{~g} / \mathrm{dL}$. Coagulation studies were elevated, with a prothrombin time of $26.1 \mathrm{~s}$, International Normalized Ratio (INR) of 2.3, and an activated partial thromboplastin time (aPTT) of $42.3 \mathrm{~s}$; however, fibrinogen was normal at $311 \mathrm{mg} /$ deciliter $(\mathrm{mg} / \mathrm{dL})$. Ddimer was dramatically elevated to 17,679 nanograms/ milliliter D-dimer units ( $\mathrm{ng} / \mathrm{ml} \mathrm{DDU})$. Lactate dehydrogenase (LDH) was elevated to 1249 units/Liter, and uric acid was low at $1.8 \mathrm{mg} / \mathrm{dL}$. Total protein was low normal at $6.0 \mathrm{~g} / \mathrm{dL}$, and albumin was low at $2.8 \mathrm{~g} / \mathrm{dL}$. Vitamin $\mathrm{K}$ was given prophylactically for increased risk of bleeding due to coagulation abnormalities.

CT of the chest showed complete consolidation of the left upper lobe, bilateral pulmonary emboli, as well as multiple wedge-shaped splenic infarcts. (Fig. 1, below). CT of the neck showed a non-occlusive venous thrombus in a right-sided internal jugular tributary vein. Head CT was normal. Trans-thoracic echocardiogram was read as normal without vegetations, but a transesophageal echocardiogram (TEE) showed a small echogenic slightly mobile mass along right side of the ventricular septum. Doppler ultrasound of the extremities showed multiple deep venous thromboses in bilateral lower and right upper extremities, (which may have accounted for the edema in the distal extremities on exam). He was transferred to the Intensive Care Unit for initial heparinization with 35 units/kilogram (U/kg) over 10 min loading dose, then a $20 \mathrm{U} / \mathrm{kg}$ intravenous drip to achieve anti-Xa levels between 0.3-0.7 international units/milliliter $(\mathrm{IU} / \mathrm{mL})$, then transferred back to the floor for continued low molecular weight heparin with enoxaparin (Lovenox) to maintain therapeutic anti-Xa levels between $0.5-1.0 \mathrm{IU} / \mathrm{mL}$. One of two blood cultures from the referring facility became positive for Rothia dentocariosa ( $R$. dentocariosa), and was initially believed to be a contaminant, since the second blood culture drawn at the same time remained negative. Upon further questioning, it was discovered that this patient had a remote history of dental surgery, but none in the recent past. However, because of the mobile mass seen on TEE, the consensus was to manage as presumed bacterial endocarditis with long-term antibiotics. Sensitivities

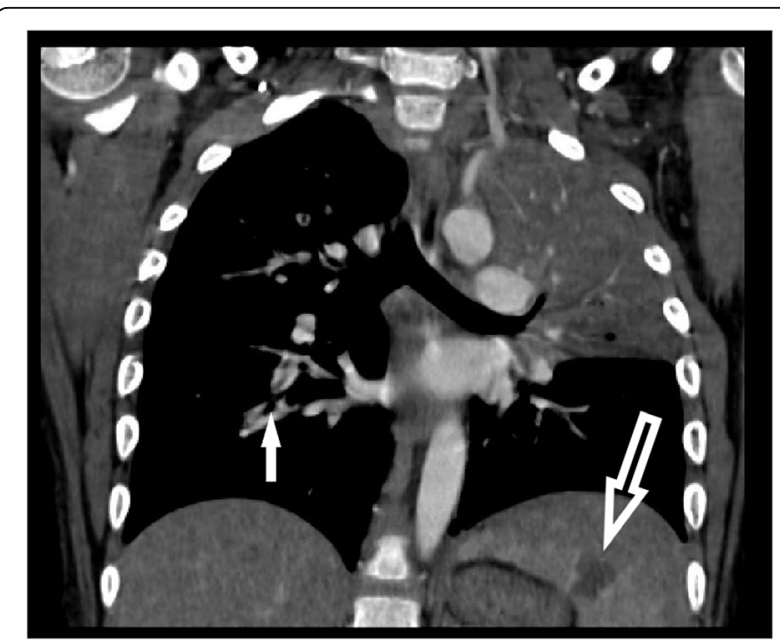

Fig. 1 CT of chest, coronal view, showing consolidation in Left upper lobe of lung, large splenic infarct (large open arrow), and filling defect of a Right pulmonary embolus (small solid arrow) 
performed on the identified $R$. dentocariosa showed sensitivity to vancomycin with a minimum inhibitory concentration (MIC) of $<=1$ microgram/milliliter $(\mathrm{mcg} / \mathrm{mL})$, and was found to be intermediately sensitive to penicillin with an MIC of $0.5 \mathrm{mcg} / \mathrm{mL}$.

On hospital day 8, his hemoglobin fell to $5.9 \mathrm{~g} / \mathrm{dL}$, requiring a red blood cell transfusion. It was believed to be a non-hemolytic anemia, as haptoglobin was elevated to $209 \mathrm{mg} / \mathrm{dL}$, LDH had normalized at 471 units/liter, and uric acid was low at the time at $2.1 \mathrm{mg} / \mathrm{dL}$. A thorough workup for clotting deficiencies was begun. All values were normal except for von Willebrand Factor and Cofactor (see Table 1 below) which were both elevated; reasons for these factors being elevated are unclear. A bone marrow aspirate and biopsy showed trilineage hematopoiesis, no pathologic cells, and were negative for malignancy.

Inflammatory markers continued to be elevated throughout his hospitalization: CRP peaked at $146.6 \mathrm{mg} /$ L, erythrocyte sedimentation rate (ESR) was $>145 \mathrm{~mm} /$ hour $(\mathrm{mm} / \mathrm{hr})$ and ferritin was $704 \mathrm{ng} / \mathrm{ml}$. Immunoglobulin (Ig) levels were found to be high and included total IgG, IgG subclasses, IgA, IgM, and M. pneumoniae specific IgG and IgM. Further investigation revealed the presence of red blood cell agglutination (cold agglutination testing was not performed) and positive lupus antinuclear antibodies with nuclear speckled and cytoplasmic patterns. All other immune workup was negative, including anti-Phospholipid antibodies (anti-beta-2 glycoproteins IgG and IgM, and anti-cardiolipin IgG and IgM) (see Table 1 below).

The problem list was expanded to include Mycoplasma pneumonia infection, bacteremia with Rothia dentocariosa, infective endocarditis from $M$. pneumoniae and/or $R$. dentocariosa, coagulopathy, bilateral pulmonary embolism, deep vein thrombosis of bilateral lower extremities and right upper extremity, multiple splenic infarcts, and a right internal jugular tributary vein thrombosis.

This patient received a 10-day course of azithromycin for the M. pneumoniae infection. For treatment of presumed infective endocarditis with $R$. dentocariosa, he was also continued on vancomycin through hospital day 9, at which time antibiotics were changed to ampicillin/ sulbactam. The ampicillin/sulbactam was continued after discharge for 8 weeks, when the ESR and CRP had returned to normal and echocardiogram showed resolution of the vegetation. He was continued on home Lovenox until echocardiogram, CT of chest, and bilateral lower extremity vascular ultrasound all showed resolution of thromboses, a total of 5 months.

On follow up, the patient is doing well. He has had no untoward sequelae. $\mathrm{He}$, his mom, and grandmother describe him as "back to normal," bored because of the pandemic, but otherwise well.

\section{Discussion and conclusions}

This case describes a patient with presumed M. pneumoniae infection. The infectious etiology is confounded by a single blood culture positive for Rothia dentocariosa. Either of these organisms could have been responsible for the presumed sepsis and endocarditis, and both infections were fully treated. While infective endocarditis and sepsis can certainly cause thromboembolic events, the added presence of $M$. pneumoniae begs the question of this organism's contribution to the vast extent of clotting seen in this patient.

There are very few cases published that involve thrombotic events associated with $M$. pneumoniae infection. Flateau et al. described a review of the literature that identified 23 patients (18 were children) with extrapulmonary thrombotic manifestations [3]. There are a few other case reports of thrombosis and infarction; some examples follow: Park et al. described a 12 year old child who died of multi-organ involvement, including myocardial infarction, in association with mycoplasma infection [4]. Choi et al. described a 5 year old boy who had an extensive stroke in multiple cerebrovascular territories 10 days after the diagnosis of M. pneumoniae infection [5]. And a 12 year old was described as having priapism, most likely due to the hypercoagulable state induced by concomitant mycoplasma infection [6]. However, there are no reports to date that describe the extensive thromboses seen in our patient. Fortunately, this patient had no CNS lesions, and recovered fully.

Although the mechanism of hypercoagulability in $M$. pneumoniae infections is unknown, several investigators have proposed different theories. It has been proposed that $M$. pneumoniae may act more like a virus than a bacterium when invading a host organism, and the host's immune responses may contribute to the pathogenesis of disease. Substances produced from pathogens, including toxins and pathogen-associated molecular patterns, as well as those produced by damaged infected host cells such as damage-associated molecular patterns, pathogenic proteins, and pathogenic peptides all contribute to the inflammatory response of the host. In Kyung-Yil Lee's proposed Protein-Homeostasis-System hypothesis, both the pathogen and the host response are responsible for disease. "Every infectious disease has its own set of toxic substances, including pathogenic proteins, associated with disease onset, and the pathogenic proteins and the corresponding immune cells may be responsible for the inflammatory processes that develop in those infectious diseases." [7] The disruption of this homeostasis produces an intense inflammatory response, and causes damage and destruction in areas unrelated to the 
Table 1 Lab Results (Bolded results are abnormal)

\begin{tabular}{|c|c|c|}
\hline Clotting Factors & Result & Reference Range \\
\hline Factor VIII & $146 \%$ & $50-150 \%$ \\
\hline Von Willebrand Factor antigen & $>200 \%$ & $60-150 \%$ \\
\hline Von Willebrand Ristocetin Cofactor & $>200 \%$ & $50-150 \%$ \\
\hline Lupus Anticoagulant Sensitive PTT & $51.5 \mathrm{~s}$, corrects with mixing & 28-47 s; No evidence of Lupus \\
\hline dRWTS (Dil Russell Viper Venom Time Screen) & $70.3 \mathrm{~s}$, corrects with mixing & $33-61 \mathrm{~s}$ \\
\hline Factor V & $121 \%$ & $50-150 \%$ \\
\hline Factor VII & $75 \%$ & $50-150 \%$ \\
\hline Factor IX & $98 \%$ & $50-150 \%$ \\
\hline Protein C Activity & $76 \%$ & $70-150 \%$ \\
\hline Protein $\mathrm{S}$ free antigen & $76 \%$ & $65-150 \%$ \\
\hline Functional Anti-thrombin III & $94 \%$ & $83-128 \%$ \\
\hline Factor V Leiden mutation & Not detected & \\
\hline PTT mixing study with heparinase & $45.5 \mathrm{~s}$ & \\
\hline Immunology & Result & Reference range \\
\hline Total Immunoglobulin (lg) lgG & $2082 \mathrm{mg} / \mathrm{dL}$ & $698-1560$ \\
\hline $\lg G 1$ & $1340 \mathrm{mg} / \mathrm{dL}$ & $309-813$ \\
\hline $\lg G 2$ & $413 \mathrm{mg} / \mathrm{dL}$ & $94-389$ \\
\hline $\lg G 3$ & $193 \mathrm{mg} / \mathrm{dL}$ & $20-100$ \\
\hline $\operatorname{lgG} 4$ & $32 \mathrm{mg} / \mathrm{dL}$ & $4-110$ \\
\hline $\lg A$ & $377 \mathrm{mg} / \mathrm{dL}$ & $81-233$ \\
\hline $\lg M$ & $425 \mathrm{mg} / \mathrm{dL}$ & $42-143$ \\
\hline Antinuclear antibodies (ANA) Screen & Positive (HEp-2 test) & Neg or $<40$ \\
\hline ANA Titer & 40 & $<40$ \\
\hline ANA Pattern & Nuclear Speckled Immunofluorescence Assay (IFA) & \\
\hline ANA Pattern 2 & Cytolplasmic IFA & \\
\hline Anti-beta-2-glycoprotein antibodies lgG & $<2 \mathrm{G}$ units & $<20$ \\
\hline Anti-beta-2-glycoprotein antibodies IgM & $<2 \mathrm{M}$ units & $<20$ \\
\hline Anti-cardiolipin IgG & $<2$ lgG Phospholipid units (GPL) & $0-23$ \\
\hline Anti-cardiolipin IgM & $<2 \mathrm{GPL}$ & $0-23$ \\
\hline Total Complement (CH50) & Normal & \\
\hline Complement C3 & $110 \mathrm{mg} / \mathrm{dL}$ & $83-157$ \\
\hline Complement C4 & $8.2 \mathrm{mg} / \mathrm{dL}$ & $13-35$ \\
\hline Total Complement (CH50) & 51 Units/mL & 40-99,999 \\
\hline Total Lymphocytes & 3597 cells/microliter & \\
\hline Absolute CD3 Count & 3273 cells/microliter & $800-3500$ \\
\hline Absolute CD4 Count & 2482 cells/microliter & $400-1200$ \\
\hline M. pneumoniae lgG & 2261 Units/ml & $0-99$ \\
\hline M. pneumoniae lgM & 5882 Units/ml & $0-769$ \\
\hline Anti-streptolysin $O$ & 810 Units/ml & $<250$ \\
\hline Aspergillus Antigen & 0.08 Index & $0.00-0.49$ \\
\hline Beta-(1,3)-D-Glucan & $<31$ picograms $/ \mathrm{mL}$ & $<80$ \\
\hline B. henselae lgG titer & Negative & Negative $=<1: 320$ \\
\hline B. henselae lgM titer & Negative & Negative $=<1: 100$ \\
\hline B. quintana lgG titer & Negative & Negative $=<1: 320$ \\
\hline
\end{tabular}


Table 1 Lab Results (Bolded results are abnormal) (Continued)

\begin{tabular}{lll}
\hline B. quintana IgM titer & Negative & Negative $=<1: 100$ \\
Urine Histoplasma antigen & None detected & Negative \\
HIV $1 \& 2$ antibody & Negreactive & Result \\
TB Quantiferon & Negative \\
Microbiology & Rothia dentocariosa \\
Blood cultures on Hospital Days 2, 3, and 4 & Negative \\
Blood culture Hospital Day 6 & Negative \\
Blood cultures Hospital Days 9 and 11 & Negative \\
Bone Marrow Biopsy Cytomegalovirus & Negative for fungal elements \\
Bone Marrow Biopsy AFB & Negative \\
Bone Marrow Biopsy GMS & Negative \\
Bronchoalveolar Lavage (BAL) viral culture & Negative \\
BAL Mycoplasma pneumoniae culture & Negative \\
BAL Cytomegalovirus (CMV) Shell Vial culture & Negative \\
BAL C. trachomatis culture & Negative for fungal elements \\
BAL Acid Fast Bacilli culture & Negative \\
BAL Calcofluor Prep & Negative \\
BAL anaerobic culture & Negative \\
BAL Pneumocystis DFA & \\
BAL CMV Shell vial isolate &
\end{tabular}

original site of infection, which could account for the wide range of extrapulmonary manifestations seen in some $M$. pneumoniae infections.

Mitsuo Narita published three possible mechanisms at work in the manifestation of extrapulmonary disease in mycoplasma infection: 1) a direct type in which bacterium is present at the site of inflammation and local inflammatory cytokines induced by the bacterium play an important role, (2) an indirect type in which the bacterium is not present at the site of inflammation and immune modulations, such as autoimmunity or formation of immune complexes, play an important role, and (3) a vascular occlusion type in which obstruction of blood flow induced either directly or indirectly by the bacterium plays an important role [8].

.Flateau et al. described how immune mediation may also play a part in the hypercoagulability seen in $M$. pneumoniae infection: "Antiphospholipid antibodies (aPL), including anticardiolipin antibodies (aCL) and lupus anticoagulant, react against proteins that bind to phospholipids on plasma membranes, contributing to thrombosis. The presence of transient aPL associated with viral, bacterial and parasitic infections is well documented, but their pathogenic role is uncertain. However, in $M$. pneumoniae infection, several cases of transient aPL associated with thrombosis have been reported, suggesting that they might actively contribute to hypercoagulability." [3].
Chapin et al. describes an association between the complement system and the coagulation cascade, as interactions between the two have been well characterized by in vitro studies. Complement pathways, especially the alternative complement pathway, are activated in hemolytic anemias and are closely linked with thrombosis [9]. Multiple coagulation proteases exhibit complements C3 and C5 convertase formation, including thrombin, coagulation factors $\mathrm{Xa}$ and XIa, and plasmin [10-12]. However, it is still unclear how the interaction of these two systems impacts the development of thrombosis.

It has long been established that $M$. pneumoniae activates agglutination of red blood cells in cold environments. Cold agglutinin mediated hemolytic anemia is a well-documented phenomenon. The cold agglutination effects of $M$. pneumoniae may also be indirectly responsible for coagulopathy and thrombosis. The association between cold agglutination and the activation of the complement cascade has been previously described [10], but the role that the coagulation cascade plays in the development of thrombotic events is not well understood.

The authors admit there are limitations to the confirmation of diagnosis of $M$. pneumoniae in this case. Many studies have compared different kits available and assay methods used for the diagnosis of $M$. pneumonia [13-15]. It is recommended that paired specific IgM and IgG serologic tests two to 4 weeks apart are needed to 
confirm M. pneumoniae [14, 16, 17]. This facility utilized an EIA assay method by GenBio for the serologic evaluation of M. pneumoniae using IgM and IgG levels, and in the case presented here a single evaluation of IgM and IgG levels was performed. Both IgM and IgG were high in this case, however the PCR was negative for $M$. pneumoniae. In most studies comparing assay methods from the different kits available, the serology is more likely to be negative early in the disease process, and shows high levels of IgM and IgG 2-4 weeks into the infection course. Since this patient had been ill for 2 weeks prior to IgM and IgG levels being drawn, it is likely that these levels reflect current infection with $M$. pneumoniae. However, it is possible that the positive results in this case are reflective of previous infection, as immunity and positive testing may last as long as $1-4$ years after infection [18].

.The patient presented here had no antiphospholipid antibodies, and had very weakly positive anti-nuclear antibodies. The significance of this is not clear. Complement testing showed no abnormalities, except for the decrease in C4 (see Table 1 below). Furthermore, while red cell agglutination was demonstrated and the presenting anemia may have been caused by a hemolytic process, the severe drop in hemoglobin on day 8 did not appear to be due to hemolysis, as LDH was normal and uric acid was low at that time. So, while there are theories about the process of the coagulopathy associated with $M$. pneumoniae infection, this case illustrates the complexity of determining the exact mechanisms involved.

This is a rare case of a child with multiple sites of thromboses in the setting of $M$. pneumoniae infection. Although the well-known association of red cell agglutination was demonstrated in this case, it was not responsible for the sudden drop in hemoglobin after 3 weeks of illness, nor does it explain the increased coagulability and multiple sites of thromboses. There were increased levels of anti-nuclear antibodies, but it is unclear if that contributed to the hypercoagulable state. Because the relationship between complement and coagulation is not well understood as of yet, the normal values for complement in this patient cannot be interpreted. It is evident from this case that more research is needed to accurately describe the phenomenon of coagulopathy and thrombosis in M. pneumoniae infections.

\footnotetext{
Abbreviations

M. pneumoniae: Mycoplasma pneumoniae; $\mathrm{mm} / \mathrm{Hg}$ : Millimeters of mercury; CRP: C-reactive protein; $\mathrm{ng} / \mathrm{mL}$ : Nanograms/milliliter; LDH: Lactate dehydrogenase; CT: Computerized tomography; $\mathrm{K} / \mathrm{mm}^{3}$ : Thousand/cubic millimeter; g/dL: Grams/deciliter; MCV: Mean corpuscular volume; $\mathrm{LL}$, or $10^{-15}$ I: Femtoliters; MCH: Mean corpuscular hemoglobin; pg: Picograms; MCHC: Mean corpuscular hemoglobin concentration; INR: International Normalized Ratio; aPTT: Activated partial thromboplastin time; mg/ dL: Milligrams/deciliter; ng/ml DDU: Nanograms/milliliter D-dimer units;
}

TEE: Trans-esophageal echocardiogram; U/kg: Units/kilogram; IU/ $\mathrm{mL}$ : International units/milliliter; $R$. dentocariosa: Rothia dentocariosa: MIC: Minimum inhibitory concentration; $\mathrm{mcg} / \mathrm{mL}$ : Microgram/milliliter; ESR: Erythrocyte sedimentation rate; Ig: Immunoglobulin; CNS: Central nervous system; ANA: Antinuclear antibodies; aPL: Antiphospholipid antibodies; aCL: Anticardiolipin antibodies; BAL: Bronchoalveolar lavage; CMV: Cytomegalovirus; dRWTS: Dil Russell Viper Venom Time Screen; IFA: Immunofluorescence Assay; GPL: IgG Phospholipid units

\section{Acknowledgements}

Madison Meder, MD reviewed and edited the paper as it was being drafted. Charles Anthony Lawrence Jr., MD helped to identify appropriate images for the publication of this case. Amy Middleman, MD and Monique Naifeh, MD reviewed and offered suggestions for editing during the drafting of this paper.

\section{Authors' contributions}

$\mathrm{DH}$ was the major contributor in writing the case report. CA and ML reviewed, edited, and formatted the paper for publication. All authors read and approved the final manuscript.

\section{Authors' information}

$\mathrm{DH}$ and $\mathrm{ML}$ are faculty in the Department of Pediatrics at the University of Oklahoma Health Sciences Center. They both are Pediatric Hospitalists, and $\mathrm{DH}$ also works in the section of General Pediatrics in the residency program's continuity clinic. $\mathrm{DH}$ and $\mathrm{ML}$ are both very involved in teaching medical students and Pediatric Residents.

CA was a resident at the University of Oklahoma who was very involved in this patient's case, and who has now graduated and is in fellowship in Allergy and Immunology at the University of North Carolina. The authors believe that this case brings information to the vast body of medical knowledge, and felt it was important to submit for publication.

\section{Availability of data and materials}

Data sharing is not applicable to this article as no datasets were generated or analyzed during the current study. The data provided in this case report was obtained from the electronic medical records of Oklahoma Children's Hospital and is protected health information. Consent for sharing this deidentified information was obtained from the parent of the patient, and is available upon request.

\section{Declarations}

Ethics approval and consent to participate

Not applicable for this case study.

\section{Consent for publication}

Written informed consent for publication of their clinical details and/or clinical images was obtained from the patient/parent/guardian/ relative of the patient. A copy of the consent form is available for review by the Editor of this journal.

\section{Competing interests}

The authors declare that they have no competing interests.

\section{Author details}

${ }^{1}$ Department of Pediatrics, University of Oklahoma Health Sciences Center, 1200 Children's Avenue, A1 Room 12305, Oklahoma City, Oklahoma 73104, USA. ${ }^{2}$ Department of Pediatrics, University of North Carolina, 030 MacNider Hall, CB 7231, Chapel Hill, North Carolina 27599-7231, USA.

Received: 12 February 2021 Accepted: 18 August 2021

Published online: 31 August 2021

\section{References}

1. Waites KB, Talkington DF. Mycoplasma pneumoniae and its role as a human pathogen. Clin Microbiol Rev. 2004;17(4):697-728.

2. Waites $\mathrm{KB}$, et al. Mycoplasma pneumoniae from the respiratory tract and beyond. Clin Microbiol Rev. 2017;30(3):747-809.

3. Flateau $C$, et al. Aortic thrombus and multiple embolisms during a Mycoplasma pneumoniae infection. Infection. 2013;41(4):867-73. 
4. Park SJ, et al. Fulminant and Fatal Multiple Organ Failure in a 12-Year-Old Boy WithMycoplasma pneumoniaelnfection. Allergy Asthma Immunol Res. 2012;4(1):55

5. Choi YH, et al. Extensive and progressive cerebral infarction after Mycoplasma pneumoniae infection. Korean J Crit Care Med. 2017;32(2):211-7.

6. Hirshberg SJ, Charles RS, Ettinger JB. Pediatric priapism associated with Mycoplasma pneumoniae. Urology. 1996;47(5):745-6.

7. Lee KY. A common immunopathogenesis mechanism for infectious diseases: the protein-homeostasis-system hypothesis. Infect Chemother. 2015;47(1):12-26

8. Narita M. Classification of Extrapulmonary manifestations due to Mycoplasma pneumoniae infection on the basis of possible pathogenesis. Front Microbiol. 2016;7(23):1-2.

9. Chapin J, et al. The role of complement activation in thrombosis and hemolytic anemias. Transfus Apher Sci. 2016:54(2):191-8.

10. Amara $\mathrm{U}$, et al. Molecular intercommunication between the complement and coagulation systems. J Immunol. 2010;185(9):5628-36.

11. Huber-Lang M, et al. Generation of C5a in the absence of C3: a new complement activation pathway. Nat Med. 2006;12(6):682-7.

12. Krisinger MJ, et al. Thrombin generates previously unidentified C5 products that support the terminal complement activation pathway. Blood. 2012; 120(8):1717-25.

13. Talkington $D F$, et al. Analysis of eight commercial enzyme immunoassay tests for detection of antibodies to Mycoplasma pneumoniae in human serum. Clin Diagn Lab Immunol. 2004;11(5):862-7.

14. Jeon HE, et al. Early confirmation of Mycoplasma pneumoniae infection by two short-term serologic lgM examination. Diagnostics. 2021;11(2):353.

15. Yoo SJ, Oh HJ, Shin BM. Evaluation of four commercial lgG- and IgM-specific enzyme immunoassays for detecting Mycoplasma pneumoniae antibody: comparison with particle agglutination assay. J Korean Med Sci. 2007;22(5): 795-801.

16. Miller $\mathrm{JM}$, et al. A guide to utilization of the microbiology laboratory for diagnosis of infectious diseases: 2018 update by the Infectious diseases society of america and the american society for microbiology. Clin Infect Dis. 2018;67(6):e1-e94.

17. Youn YS, Lee KY. Mycoplasma pneumoniae pneumonia in children. Korean J Pediatr. 2012:55(2):42-7.

18. Yu J, et al. Distributions of antibody titers to mycoplasma pneumoniae in Korean children in 2000-2003. J Korean Med Sci. 2005:20(4):542-7.

\section{Publisher's Note}

Springer Nature remains neutral with regard to jurisdictional claims in published maps and institutional affiliations.

Ready to submit your research? Choose BMC and benefit from:

- fast, convenient online submission

- thorough peer review by experienced researchers in your field

- rapid publication on acceptance

- support for research data, including large and complex data types

- gold Open Access which fosters wider collaboration and increased citations

- maximum visibility for your research: over $100 \mathrm{M}$ website views per year

At $\mathrm{BMC}$, research is always in progress.

Learn more biomedcentral.com/submissions 